\title{
Peer education for HIV prevention among high-risk groups: a systematic review and meta-analysis
}

\author{
Jiayu He $\mathrm{He}^{1,2,{ }^{\dagger}}$, Ying Wang ${ }^{1 \dagger}$, Zhicheng Du${ }^{1}$, Jing Liao ${ }^{1}, \mathrm{Na} \mathrm{He}^{2,3}$ and Yuantao Hao ${ }^{1 *}$
}

\begin{abstract}
Background: Peer education has become a strategy for health promotion among high-risk groups for HIV infection worldwide. However, the extent to which peer education could have an impact on HIV prevention or the longterm effect of this impact is still unknown. This study thus quantifies the impact of peer education over time among high-risk HIV groups globally.

Method: Following the PRISMA guidelines, a systematic review and meta-analysis was used to assess the effects and duration of peer education. A thorough literature search of PubMed, Web of Science, Embase and Cochrane Library was performed, and studies about peer education on high-risk HIV groups were reviewed. Pooled effects were calculated and the sources of heterogeneity were explored using meta-regression and subgroup analysis.

Results: A total of 60 articles with 96,484 subjects were identified, and peer education was associated with 36\% decreased rates of HIV infection among overall high risk groups (OR: 0.64; 95\%Cl: 0.47-0.87). Peer education can promote HIV testing $(\mathrm{OR}=3.19 ; 95 \% \mathrm{Cl}: 2.13,4.79)$ and condom use $(\mathrm{OR}=2.66,95 \% \mathrm{Cl}: 2.11-3.36)$ while reduce equipment sharing $(\mathrm{OR}=0.50 ; 95 \% \mathrm{Cl}: 0.33,0.75)$ and unprotected sex $(\mathrm{OR}=0.82 ; 95 \% \mathrm{Cl}$ : $0.72-0.94)$. Time trend analysis revealed that peer education had a consistent effect on behavior change for over 24 months and the different follow-up times were a source of heterogeneity.
\end{abstract}

Conclusion: Our study shows that peer education is an effective tool with long-term impact for behavior change among high-risk HIV groups worldwide. Low and middle-income countries are encouraged to conduct large-scale peer education.

Keywords: Peer education, High risk HIV groups, Meta-analysis

\section{Background}

Acquired immune deficiency disease (AIDS), caused by the human immunodeficiency virus (HIV) is a severe infectious disease. High risk HIV groups, including men who have sex with men (MSM), people who inject drugs (IDUs) and female sex workers (FSWs) are those who have high-risk behaviors and thus tend to be disproportionately infected by HIV virus [1]. As the 2018 Joint

\footnotetext{
* Correspondence: haoyt@mail.sysu.edu.cn

† Jiayu He and Ying Wang contributed equally to this work.

'Department of Medical Statistics and Epidemiology, School of Public Health, Sun Yat-sen University, Guangzhou 510080, Guangdong Province, China Full list of author information is available at the end of the article
}

United Nations Program on HIV/AIDS reported, such high risk groups and their sexual partners accounted for $47 \%$ of new HIV infections globally [1]. Compared with the general population, MSM have a 27 times higher infection risk of HIV, IDUs 23 times, and FSWs 13 times [2]. These groups also have a series of high-risk behaviors, such as unprotected sex [2], failing to get HIV tests [3] and sharing drug equipment [4]. Effective behavioral intervention strategies are therefore urgently needed for health promotion among them. One of the key approaches is peer education [5-7].

(c) The Author(s). 2020 Open Access This article is licensed under a Creative Commons Attribution 4.0 International License, which permits use, sharing, adaptation, distribution and reproduction in any medium or format, as long as you give appropriate credit to the original author(s) and the source, provide a link to the Creative Commons licence, and indicate if changes were made. The images or other third party material in this article are included in the article's Creative Commons licence, unless indicated otherwise in a credit line to the material. If material is not included in the article's Creative Commons licence and your intended use is not permitted by statutory regulation or exceeds the permitted use, you will need to obtain permission directly from the copyright holder. To view a copy of this licence, visit http://creativecommons.org/licenses/by/4.0/ The Creative Commons Public Domain Dedication waiver (http://creativecommons.org/publicdomain/zero/1.0/) applies to the data made available in this article, unless otherwise stated in a credit line to the data. 
Peer education is a common strategy for preventing HIV and promoting health worldwide [8] and typically involves recruiting members of a specific at-risk group to encourage members to change risky sexual behaviors and maintain healthy sexual behaviors [9]. What distinguishes peer education from mass media programs is that there is more interpersonal interaction in both directions [9]. Peers are much more likely to influence the behavior of fellow group members since they are assumed to be able to gain a level of trust, which allows for more open discussions on sensitive topics $[10,11]$. They also have better access to hidden populations who may have limited interaction with traditional health programs [12]. Finally, they are cost effective in comparison with traditional healthcare providers $[13,14]$.

Previous studies have shown that peer education could reduce risk behaviors $[15,16]$ and promote health [17-21], but some researchers measured the influence of peer-based intervention on conversations about HIV prevention and highlighted the effect declined and the frequency of conversations on the topics decreased [22]. Previous meta-analyses only synthesized the effect of peer education in developing countries in general population [8] and only revealed the effect of peer education on condom use [17] or HIV testing [23] among MSM groups. What's more, it is also still unclear whether peer education can bring about positive effects and maintain the changes consistently among different high risk HIV groups both in developed and developing countries.

Consequently, an up-to-date and comprehensive systematic review and meta-analysis is urgently needed to evaluate the effect of peer education on different behaviors among high risk groups. To address these issues, we conducted a systematic review and meta-analysis to examine and summarize the effects of peer education on different behaviors, including condom use, HIV testing, unprotected sex, equipment sharing and, HIV incidence both in developed and developing countries among high risk HIV groups. We also conducted a time analysis of peer education to measure its persistent effects over time.

\section{Methods}

\section{Search strategy}

This systematic review was conducted in accordance with the Preferred Reporting Items for Systematic Reviews and Meta-Analyses (PRISMA) [15]. The literature was searched using four electronic databases: PubMed, Web of Science, EMBASE, and the Cochrane Library. The search included all the literature published from January 2000 to April 2019. We used the search terms ("peer education" OR "peer-led intervention" OR "peer counseling" OR "peer approaches") AND ("HIV” OR
"AIDS") AND ("MSM" OR "homosexual" OR "IDUs" OR "drug users" OR "FSWs" OR "female entertainment workers"). References of retrieved full-text articles and other reviews were screened for additional eligible publications. All publications were exported to a NoteExpress file and the duplicates were deleted.

\section{Study selection and eligibility criteria}

Studies were selected if they met the following inclusion criteria: (1) peer education intervention related; (2) the intervention was conducted in high-risk HIV groups, including MSM, IDUs and FSWs; (3) original RCTs or quasiexperimental intervention studies or post-intervention studies or serial cross-sectional intervention studies with quantitative data; (4) behavioral, psychological or social outcome(s) related to HIV health promotion; and (5) the article was published in a peer-reviewed journal from January 2000 to April 2019, without language restrictions. We defined peers as demographically-similar counterparts of the target population. Studies were excluded if they were: (1) review or qualitative studies; (2) not presenting outcome data after peer education; (3) conference abstracts or brief reports.

The titles and abstracts were independently reviewed by two authors (He JY and Wang Y), and full texts of potentially eligible studies were downloaded and further screened for final inclusion in our study. When there was uncertainty or disagreement between the two authors as to the eligibility of a study, another author (Hao YT) was invited for guidance in reaching a consensus.

\section{Data extraction}

All data were extracted independently by two authors (He JY and Wang Y) using common abstraction forms. The characteristics recorded for each eligible study included the first author's name, publication year, study country, study object, mean age of participants, study design, sample sizes, description of intervention in study aims and comparison aims, duration of follow-up, study outcomes, number of events in trial and control groups, outcome indicators, and 95\% confidence intervals (CIs).

We then performed a quality assessment of each study included using an 8-point scale which was first used in a meta-analysis in 2009 [8] and has subsequently been cited by other researchers [24-27]. One point was awarded for each of the following items: (1) prospective cohort; (2) control or comparison group; (3) pre/post intervention data; (4) random assignment of participants to the intervention; (5) follow-up rate of $80 \%$ or more; (6) comparison groups equivalent in terms of social-demographic measures; (7) comparison groups equivalent at baseline in terms 
of outcome measures; and (8) sample size $\geq 100$. Therefore, the total rigor score for each study ranged from 0 to 8 .

\section{Statistical analysis}

Meta-analysis was performed using the package 'meta' in $\mathrm{R}$ software (version 3.4.3). We converted effect size estimates to the common metric of an odds ratio (OR). ORs and their 95\% CIs were extracted directly from reports when available, with adjusted ORs extracted preferentially over unadjusted ORs. If an included study did not report ORs, crude ORs were calculated from extracted data.

The $I^{2}$ statistic was used to assess the level of heterogeneity across included studies, with values of 50 , and $75 \%$ representing low to moderate, and high heterogeneity, respectively [16]. Both a fixed-effect model for low heterogeneity studies and a random-effect model for moderate and high heterogeneity studies were used to calculate pooled effect sizes. We explored sources of heterogeneity by performing subgroup analyses among different high risk groups. If substantial heterogeneity was detected $\left(I^{2}>90\right)$, we performed multivariate meta-regression analyses to investigate the proportion of study variance accounted for by country, follow-up time, and high risk groups. Publication bias was assessed using funnel plots and Egger's test [28]. We also performed sensitivity analyses by removing one study at a time and recalculating the pooled estimates.

In order to evaluate the time effect of intervention, we developed subgroup analyses of different follow-up times. Different studies reported outcome effects at different follow-up times. Therefore, we conducted meta-analyses of different duration for each intervention result based on the principle of making full use of the information: (1) unprotected sex behavior: 3, 6 and 12 months, (2) equipment sharing behavior: 3, 6, 12, and 24 months, (3) HIV testing behavior: 3, 6, 12, and 24 months, (4) condom use behavior: 3, 6, 12, 24, 36, 48 months, (5) HIV infection: 12, 24, and 48 months. Combined ORs of outcome were calculated in each group. Line charts of combined ORs on each intervention result were conducted to see whether the effect of peer education appeared to decline over time.

\section{Selection of study endpoints}

A meta-analysis was conducted on four behavioral outcomes and one biological outcome which were reported across multiple studies: HIV testing, condom use, injection drug equipment sharing, unprotected sex, and HIV measure. HIV testing was the dichotomous proportion of respondents who did or did not have an HIV test.
Condom use was always measured as a multiple categorical variable in the studies, such as used condom in last sexual encounter, always used condom, used condom with clients, used condom with sexual partners etc. We prioritized the general and comprehensive variable which can most reduce risk and represent the most cases, such as always used condom. We also conducted subgroup analyses on condom use including condom use with regular partners, condom use with casual partners and consistent condom use. Intravenous drug equipment sharing included reported episodes of sharing needles/syringes, rinse water, and/or cooking utensils. HIV measures including incidence and prevalence, were measured by self-reports, chart reviews, and clinical diagnoses. For all outcomes, our selection of the outcomes to be included in the meta-analysis prioritized the comparison with the longest follow-up time.

\section{Results}

\section{Search and description of studies}

The initial search of our chosen four electronic databases yielded 1499 articles; of which 274 duplicates were removed. Of the remaining 1225, 1064 were excluded due to lack of relevance to peer education, the target population i.e. not HIV risk groups, or because they were reviews. Full text screening of the remaining 131 papers led to the further exclusion of 64 papers for the following reasons: lack of information on target outcomes $(n=26)$, not a peer-led intervention $(n=36)$, and two articles could not be downloaded. Thus, 60 studies met our predefined inclusion criteria (Fig. 1). One of these 60 studies was not included in the meta-analysis because it lacked quantitative data. The characteristics of each study are detailed in Table 1 . The information of the selected studies can be found at Supplemental material 1.

Of these 60 studies, 34 articles employed randomized controlled trials or quasi-experiments, and 9 articles were cohort studies. The remaining 18 studies were serial cross-sectional studies. As shown in Table 1, 25 studies were conducted in East and Southeast Asia, 9 in Central Asia, 15 in North America, eight in Africa, 7 in Europe, and one in South America with some studies conducted across two countries.

Target populations included MSM $(n=18)[12,17-21$, 32-43], injected drug users $(n=22)$ [22, 44-64], female sexual workers $(n=20)$ [29-31, 65-80]. The included studies were undertaken between 2001 and 2009, and the population number ranged from 69 to 7015. Mean or median age varied from 16 to 43 years. Study quality assessment scores ranged from 2 to 8 , with a mean score of 5.05 out of 8 which is the most rigorous (Supplemental Table 1). According to the sensitivity analysis, the results were robust after moving each study (Supplemental Figure 1, 2, 3, 4, 5, 6, 7, 8) and the Egger tests indicated 
that there was no publication bias, which are shown in the supplemental material (Supplemental Table 2).

\section{Impact of peer education on outcome measures}

Table 2 presents a summary of the pooled effect sizes for the five outcomes, including overall effects, effects stratified by the three target populations, as well as the level of a country's economic/social development.

\section{HIV testing}

Fifteen studies $[18,19,22,30-32,34,35,39,43,51,76$, $79,80]$ reported the quantitative outcomes on HIV testing with a combined study population of 12,775 and two studies did not show an increase rate of HIV testing. The outcome of the random effect model suggested that the effect was significant (OR: 3.19; 95\%CI: 2.13-4.79) with substantial heterogeneity across studies $\left(I^{2}=92 \%\right)$. This thus indicates that the peer education was able to increase the rate of HIV testing among high risk HIV groups globally (Fig. 2).

\section{Equipment sharing}

Sixteen studies $[22,45-47,49-55,57-59,61,62]$ generated 17 discrete effect sizes on equipment sharing with a combined study population of 13,830 . Although seven of the sixteen studies reported non-significant changes in equipment sharing before and after intervention, the outcome of the random effect model indicated that the overall effect was significant (OR: 0.52; 95\%CI: $0.35-$ $0.76)$ with substantial heterogeneity across studies $\left(I^{2}=\right.$ 93\%). The meta-analysis of these 16 articles suggested that through peer education, IDUs would reduce equipment sharing (Fig. 3).

\section{Unprotected sex}

Ten studies generated $[17,20,29,42,43,46,55,57-59]$ 11 independent effect sizes on unprotected sex with a combined study population of 6289. Four of the articles showed a significant reduction in unprotected sex, while four of the articles showed a non-significant reduction. Another three studies found no changes before and after peer education intervention. The fixed effect meta-

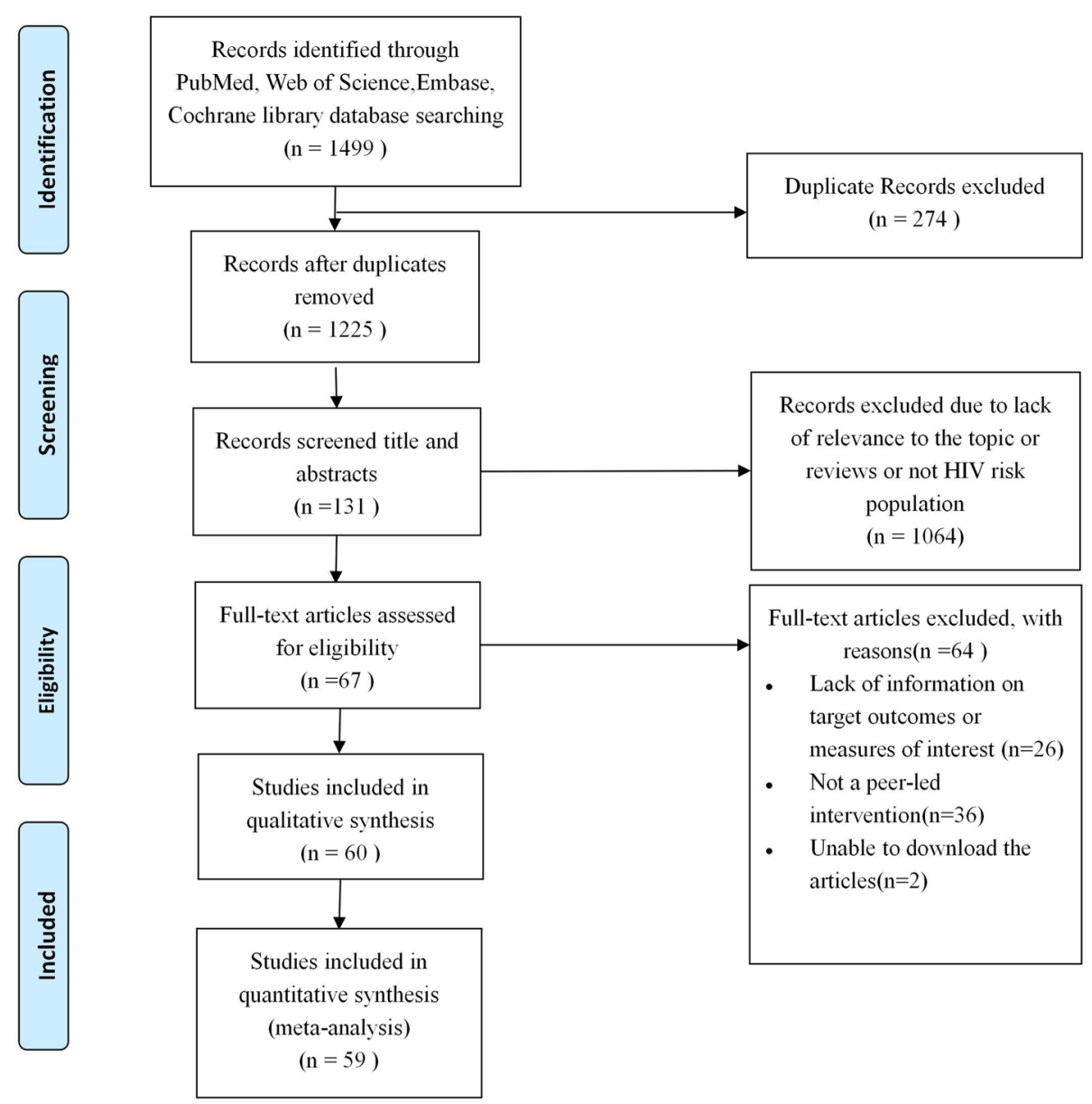

Fig. 1 Flow chart of literature search and selection of studies 


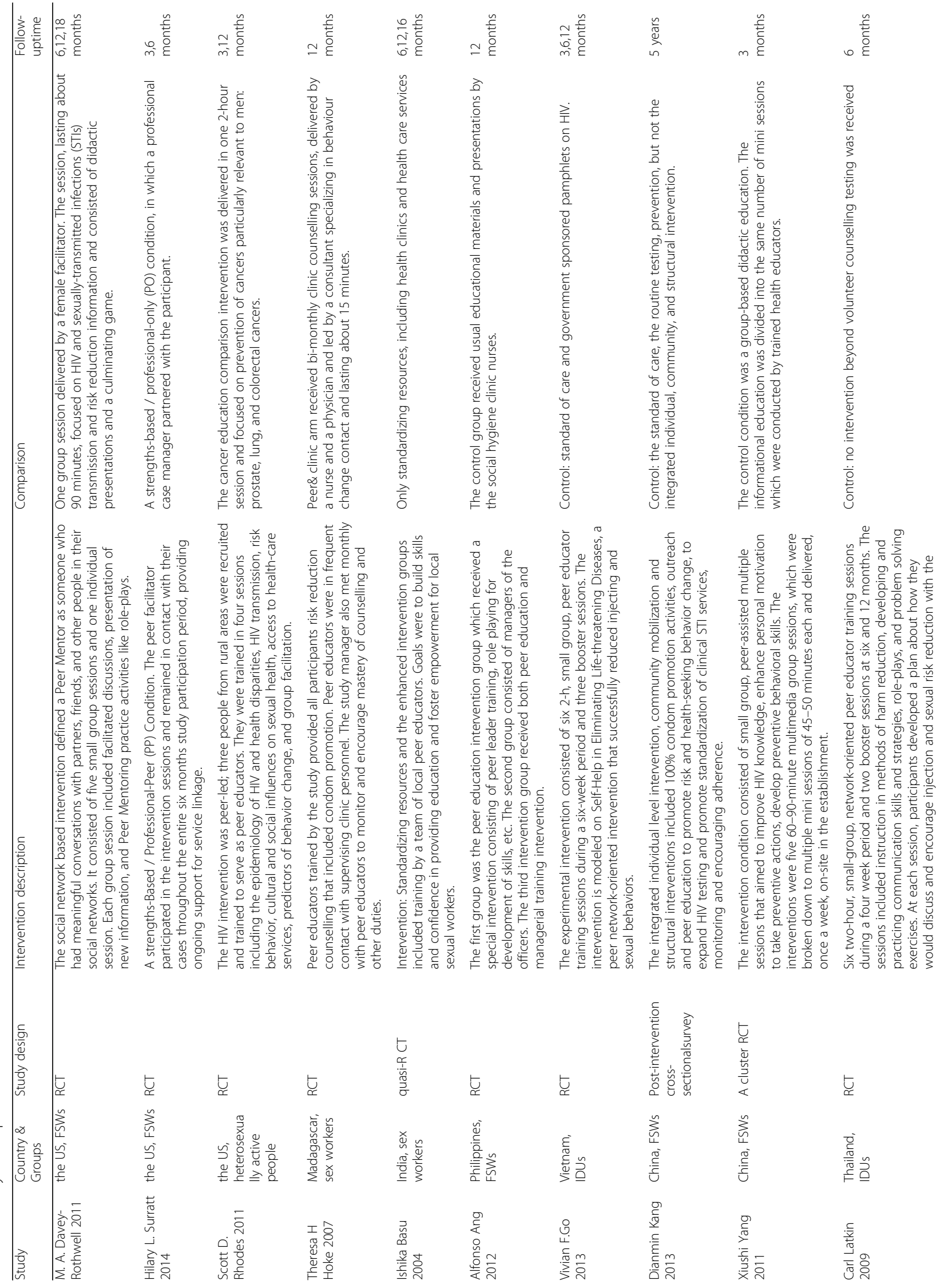




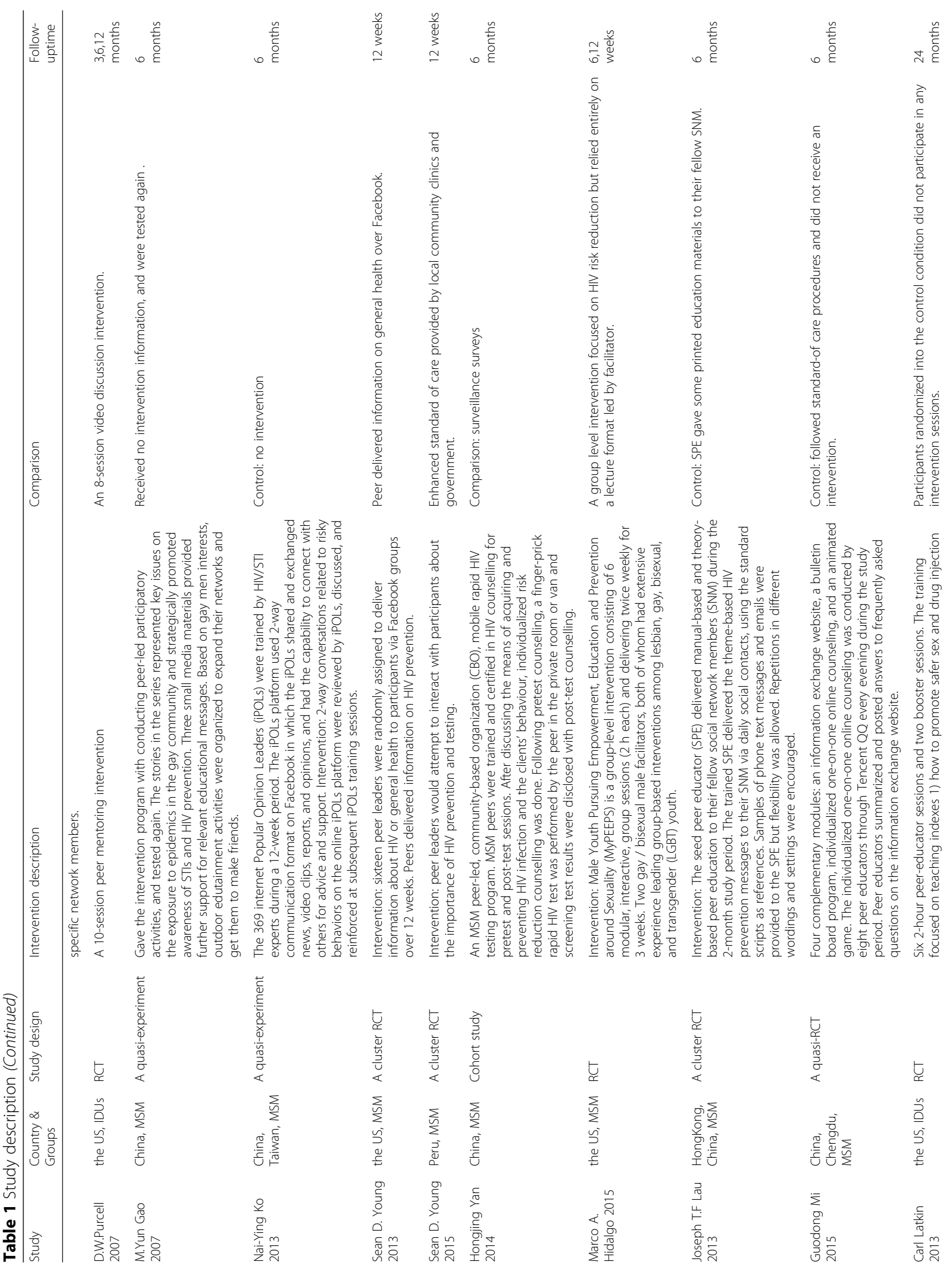




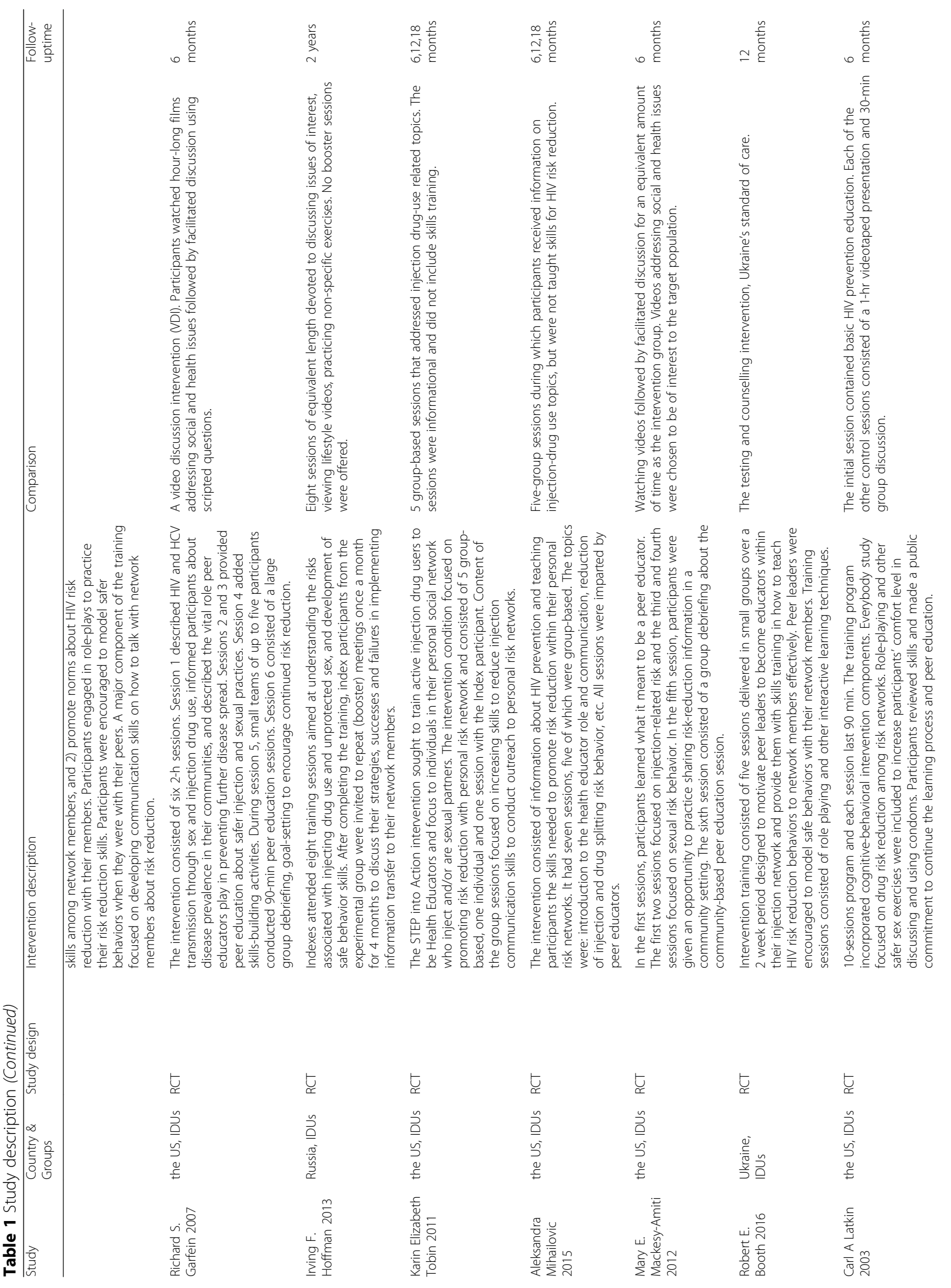




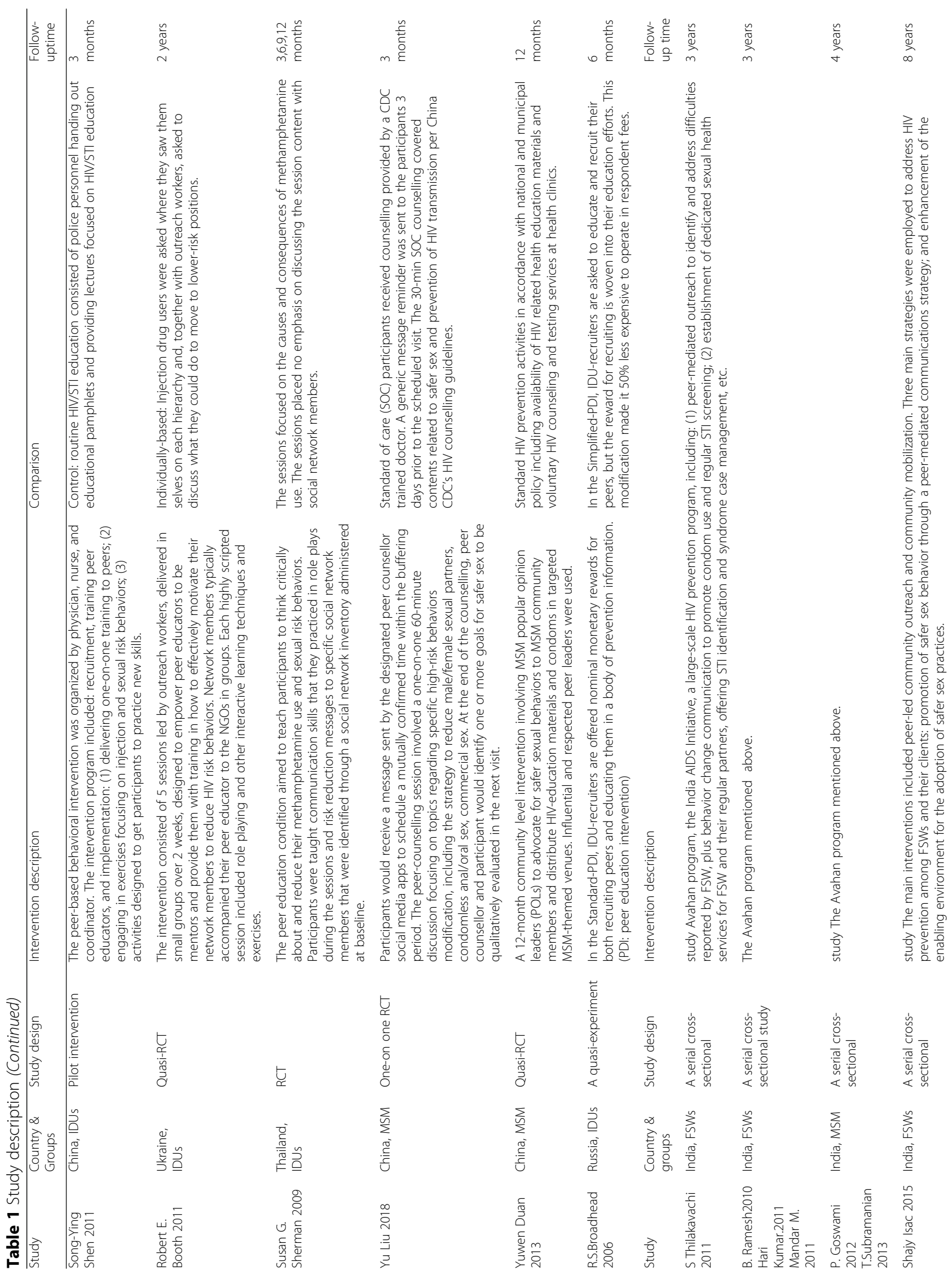




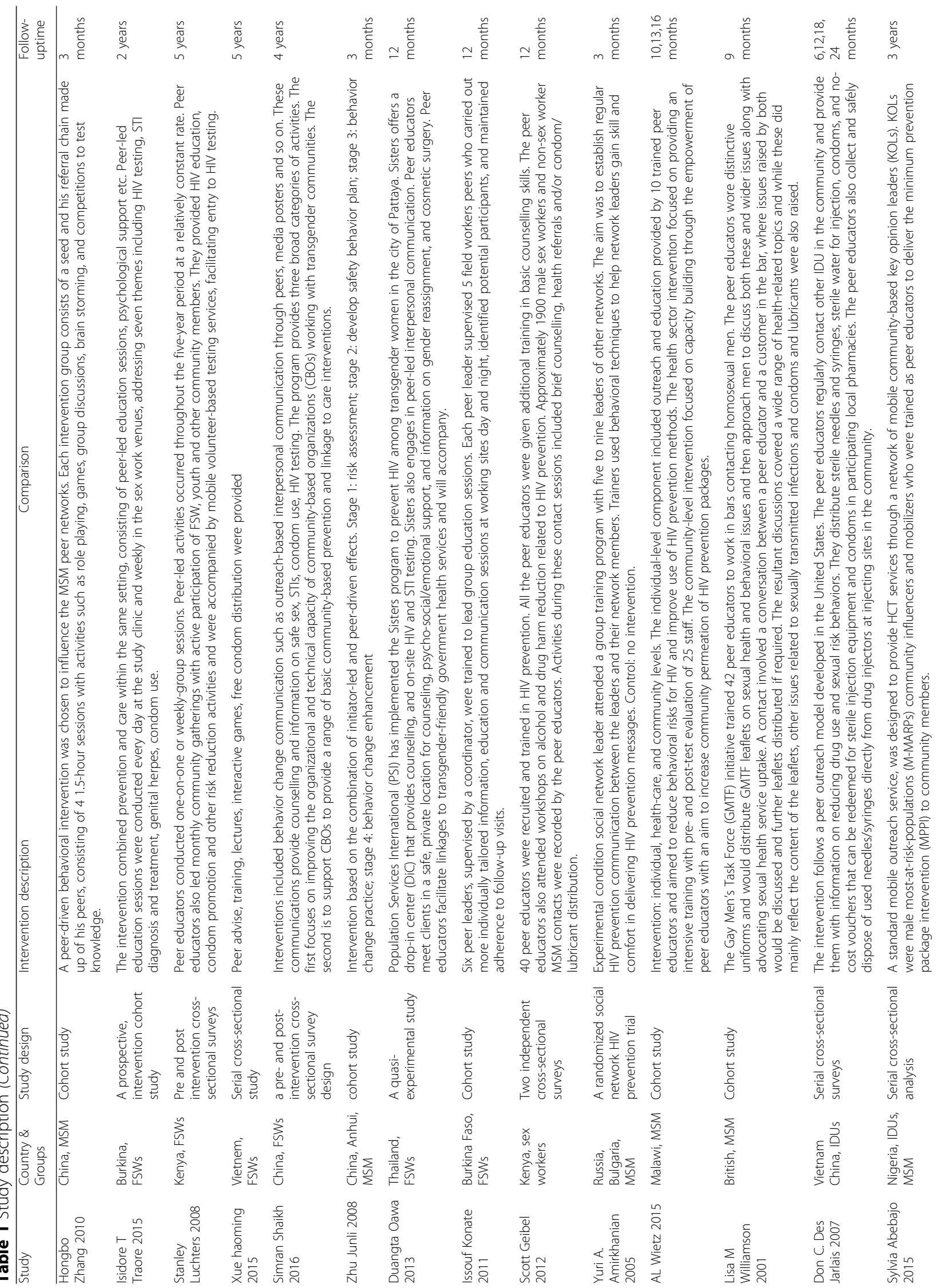




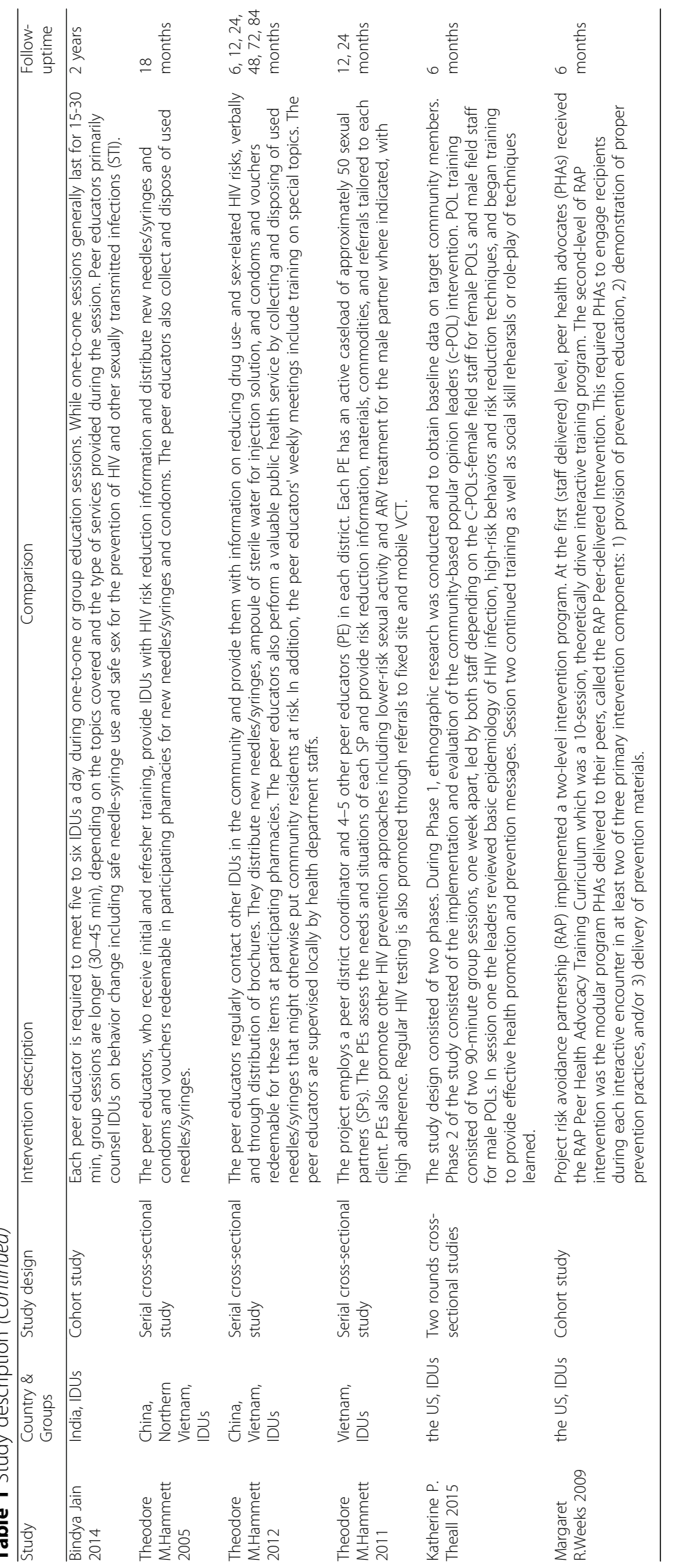




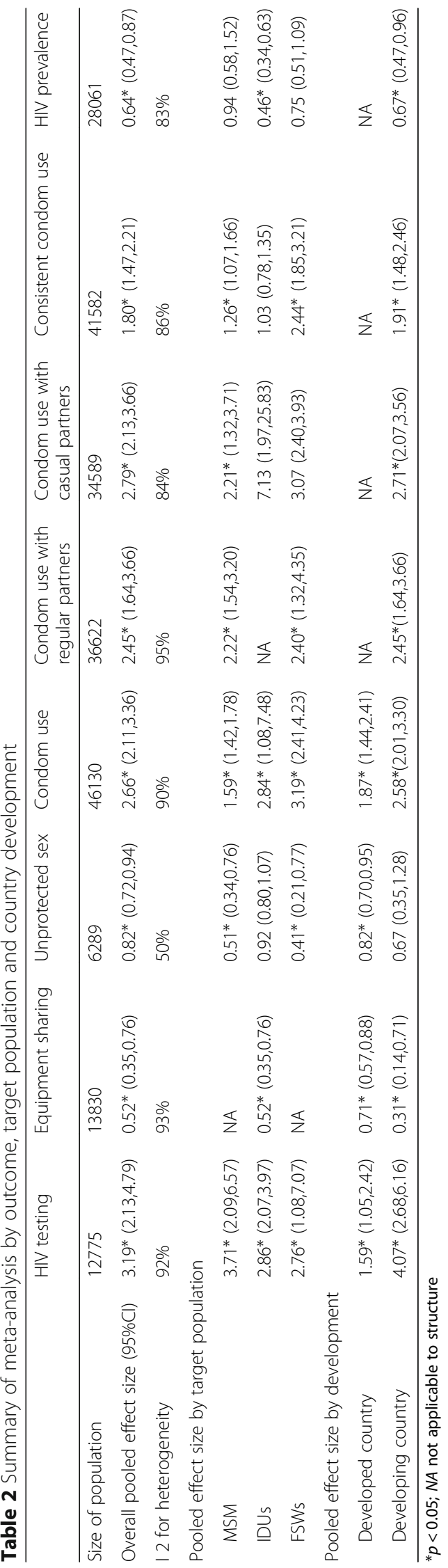


analysis model showed that peer education lowered $18 \%$ of unprotected sex among high risk groups worldwide (OR: 0.82; 95\%CI: 0.72-0.94; $I^{2}=50 \%$ ) (Fig. 4).

\section{Condom use}

Thirty-two studies $[19,22,31-34,36-41,51,53,56,63$, $65,66,68-80$ ] reported a condom use outcome after intervention with a population of 46,130. Results across these studies were mixed but most revealed an increase in condom use, and only six of the 32 studies showed insignificant condom use after intervention. In general, after the peer education intervention, condom use among the HIV risk population increased with a combined OR of 2.66 (95\%CI: 2.11-3.36; $I^{2}=90 \%$ ) (Fig. 5). Subgroup analyses also demonstrated significant results among FSWs, MSM and IDUs, with a pooled OR effect of 3.19 (95\%CI: 2.41-4.23; $I^{2}=88 \%$ ), 1.76 (95\%CI:1.37-2.26; $I^{2}=72 \%$ ) and 2.84 (95\%CI: $1.08-$ $\left.7.48 ; I^{2}=95\right)$ respectively, which indicated a positive effect of peer education on condom use (Supplemental figure 9, 10, 11).

Subgroup analyses were also carried out by different partner types and using patterns, revealing that peer-led intervention increased condom use both with casual sexual partners (OR: 2.79; 95\%CI: $2.13-3.66 ; I^{2}=84 \%$ ) and regular sexual partners (OR: 2.45; 95\%CI: 1.64-3.66; $\left.I^{2}=95 \%\right)$. Considering that consistent condom use had a more profound impact on preventing HIV, we also conducted a meta-analysis and found it increased after peer education (OR: 1.80; 95\%CI: $1.47-2.21 ; I^{2}=86 \%$ ) (Supplemental figure 12, 13, 14).

\section{HIV measures}

Nine studies [37, 48, 60, 64, 69, 70, 72, 73] generated 10 independent effect sizes on the HIV measure with a population of 28,061. Five showed an insignificant reduction in HIV measure after prevention, and one study found an increased odds of HIV infection. However, the overall results of the meta-analysis suggested $36 \%$ lower odds of HIV measure in high risk groups (OR: 0.64; 95\%CI: $0.47-0.87 ; I^{2}=83 \%$ ) (Fig. 6).

\section{Duration effect of peer education}

Figure 7 presents the effectiveness of peer education among high risk groups for the five outcomes at different time periods.

\section{Unprotected sex}

The follow-up time of the articles reporting the outcome of unprotected sex was mainly within 12 months of peer education, thus we only analyzed the time effect of unprotected sex at 3, 6, and 12 months. The results highlighted a non-significant effect after 3 and 6 months, with a pooled OR of 0.68 (95\% CI: $0.37-1.26)$ and 0.93 (95\% CI:0.80-1.08) respectively.

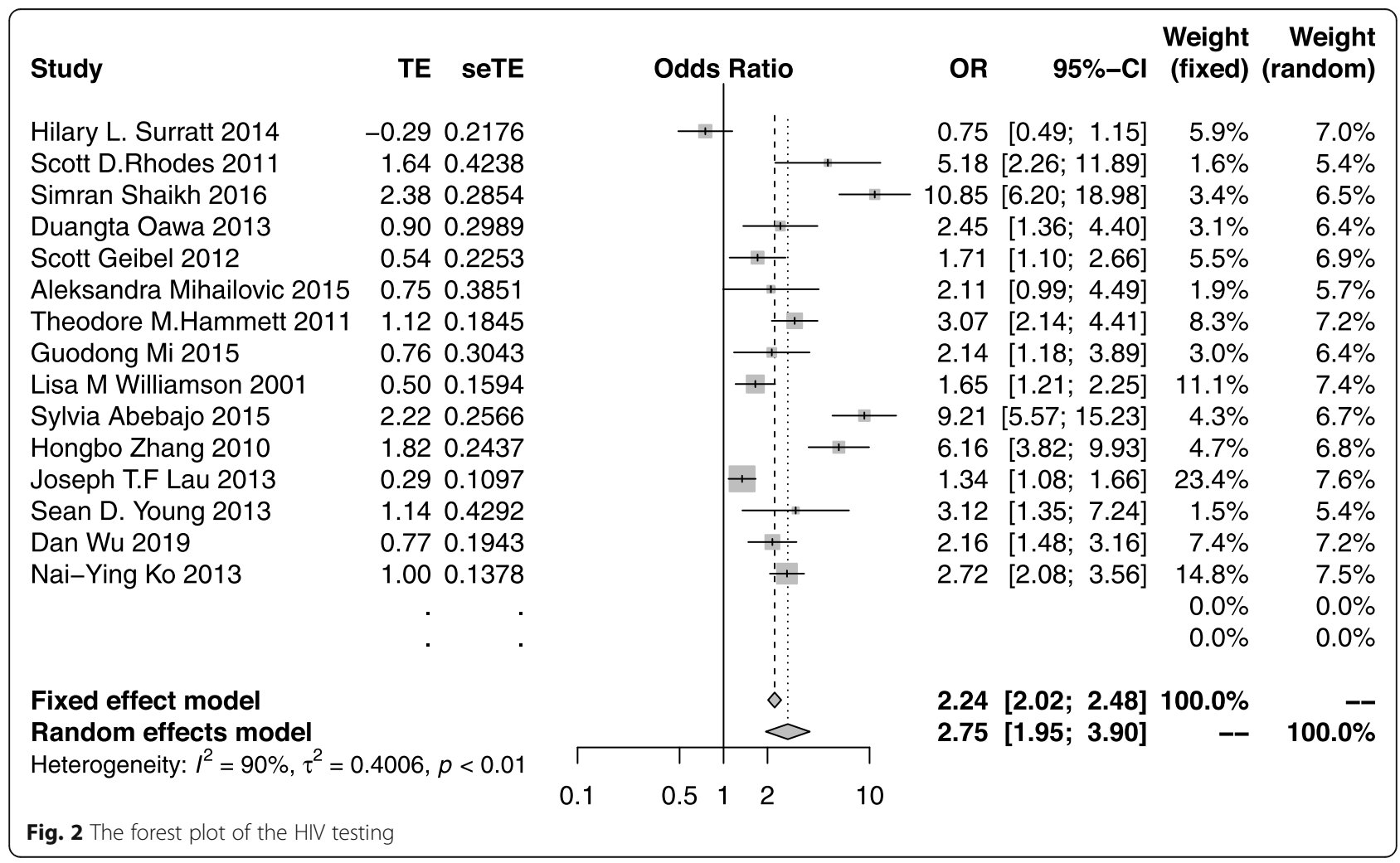




\begin{tabular}{|c|c|c|c|c|c|c|c|c|c|c|}
\hline Study & TE & seTE & & Odds $F$ & Ratio & & OR & $95 \%-\mathrm{Cl}$ & $\begin{array}{c}\text { Weight } \\
\text { (fixed) }\end{array}$ & $\begin{array}{r}\text { Weight } \\
\text { (random) }\end{array}$ \\
\hline Aleksandra Mihailovic 2015 & 0.48 & 0.3796 & & & & & 1.62 & {$[0.77 ; 3.41]$} & $1.7 \%$ & $5.6 \%$ \\
\hline Bindya Jain 2014 & -0.69 & 0.2502 & & $\rightarrow$ & & & 0.50 & {$[0.31 ; 0.82]$} & $3.9 \%$ & $6.3 \%$ \\
\hline Carl Latkin 2009-2 & 0.19 & 0.4096 & & & & & 1.21 & {$[0.54 ; 2.70]$} & $1.5 \%$ & $5.4 \%$ \\
\hline Carl Latkin 2013 & 0.17 & 0.3796 & & & 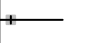 & & 1.18 & {$[0.56 ; 2.48]$} & $1.7 \%$ & $5.6 \%$ \\
\hline David W. Purcell 2007 & -0.26 & 0.3090 & & & & & 0.77 & {$[0.42 ; 1.41]$} & $2.6 \%$ & $6.0 \%$ \\
\hline Karin Elizabeth Tobin 2011 & -0.97 & 0.3708 & & 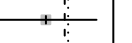 & & & 0.38 & {$[0.18 ; 0.79]$} & $1.8 \%$ & $5.7 \%$ \\
\hline Margaret R.Weeks 2009 & -0.99 & 0.2162 & & 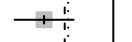 & & & 0.37 & {$[0.24 ; 0.57]$} & $5.2 \%$ & $6.5 \%$ \\
\hline Mary E. Mackesy-Amiti 2012 & -0.69 & 0.1264 & & $\frac{1}{1}$ & & & 0.50 & [0.39; 0.64] & $15.3 \%$ & $6.9 \%$ \\
\hline Richard S.Garfein 2007 & -0.45 & 0.1937 & & $\frac{i+1}{i+1}$ & & & 0.64 & {$[0.44 ; 0.94]$} & $6.5 \%$ & $6.6 \%$ \\
\hline Robert E.Booth 2011 & -0.40 & 0.1066 & & $=$ & & & 0.67 & {$[0.54 ; 0.83]$} & $21.5 \%$ & $6.9 \%$ \\
\hline Robert S.Broadhead 2006 & -0.01 & 0.1859 & & & & & 0.99 & {$[0.69 ; 1.43]$} & $7.1 \%$ & $6.6 \%$ \\
\hline Song-Ying Shen 2011 & -0.15 & 1.1626 & & & & & 0.86 & {$[0.09 ; 8.40]$} & $0.2 \%$ & $2.1 \%$ \\
\hline Theodore M.Hammett 2005 & -0.97 & 0.1672 & & 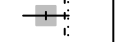 & & & 0.38 & {$[0.27 ; 0.53]$} & $8.7 \%$ & $6.7 \%$ \\
\hline Theodore M.Hammett 2012-1 & -2.81 & 0.2069 & & & & & 0.06 & {$[0.04 ; 0.09]$} & $5.7 \%$ & $6.6 \%$ \\
\hline Theodore M.Hammett 2012-2 & -2.04 & 0.1906 & $\mp$ & & & & 0.13 & {$[0.09 ; 0.19]$} & $6.7 \%$ & $6.6 \%$ \\
\hline Vivian F.Go 2013 & -0.73 & 0.8667 & & & & & 0.48 & {$[0.09 ; 2.62]$} & $0.3 \%$ & $3.0 \%$ \\
\hline \multirow[t]{3}{*}{ Carl Latkin 2009-1 } & -0.01 & 0.1604 & & t & & & 0.99 & {$[0.72 ; 1.36]$} & $9.5 \%$ & $6.7 \%$ \\
\hline & & & & & & & & & $0.0 \%$ & $0.0 \%$ \\
\hline & & & & & & & & & $0.0 \%$ & $0.0 \%$ \\
\hline \multicolumn{3}{|l|}{ Fixed effect model } & & 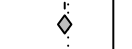 & & & 0.50 & {$[0.45 ; 0.55]$} & $100.0 \%$ & - \\
\hline \multicolumn{3}{|l|}{ Random effects model } & & $\infty$ & & & 0.52 & {$[0.35 ; 0.77]$} & - & $100.0 \%$ \\
\hline \multirow{2}{*}{\multicolumn{3}{|c|}{ Heterogeneity: $I^{2}=93 \%, \tau^{2}=0.5673, p<0.01$}} & 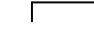 & & 1 & & & & & \\
\hline & & & 0.1 & 0.51 & 12 & 10 & & & & \\
\hline
\end{tabular}

However, a significant effect was found after 12 months of peer education, justifying its ability to reduce the cases of unprotected sex in the long term (OR:0.64; 95\% CI:0.52-0.80).

\section{Equipment sharing}

Peer education had a non-significant impact on reducing equipment sharing behaviors within 12 months however the pooled odds ratio showed a downward trend. After

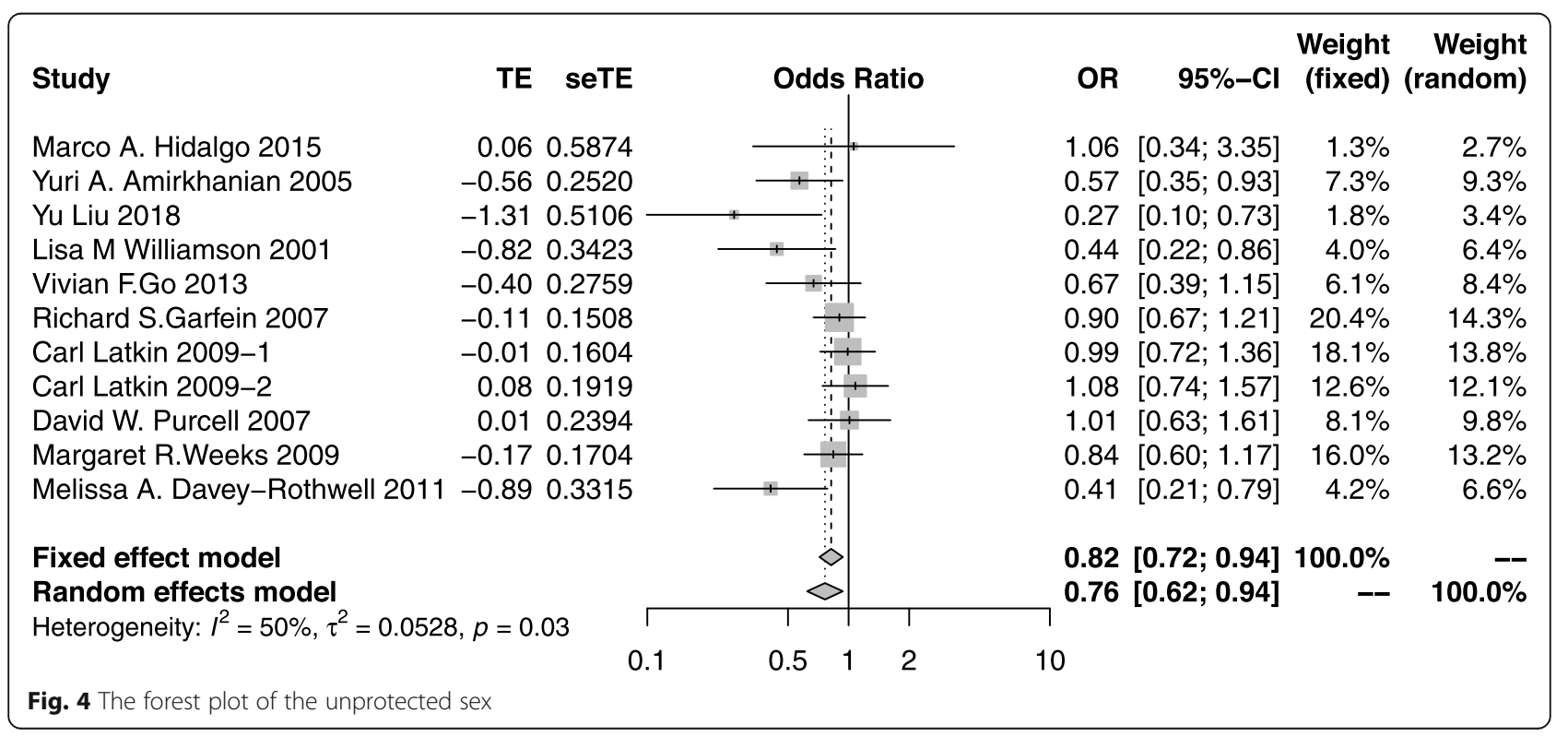




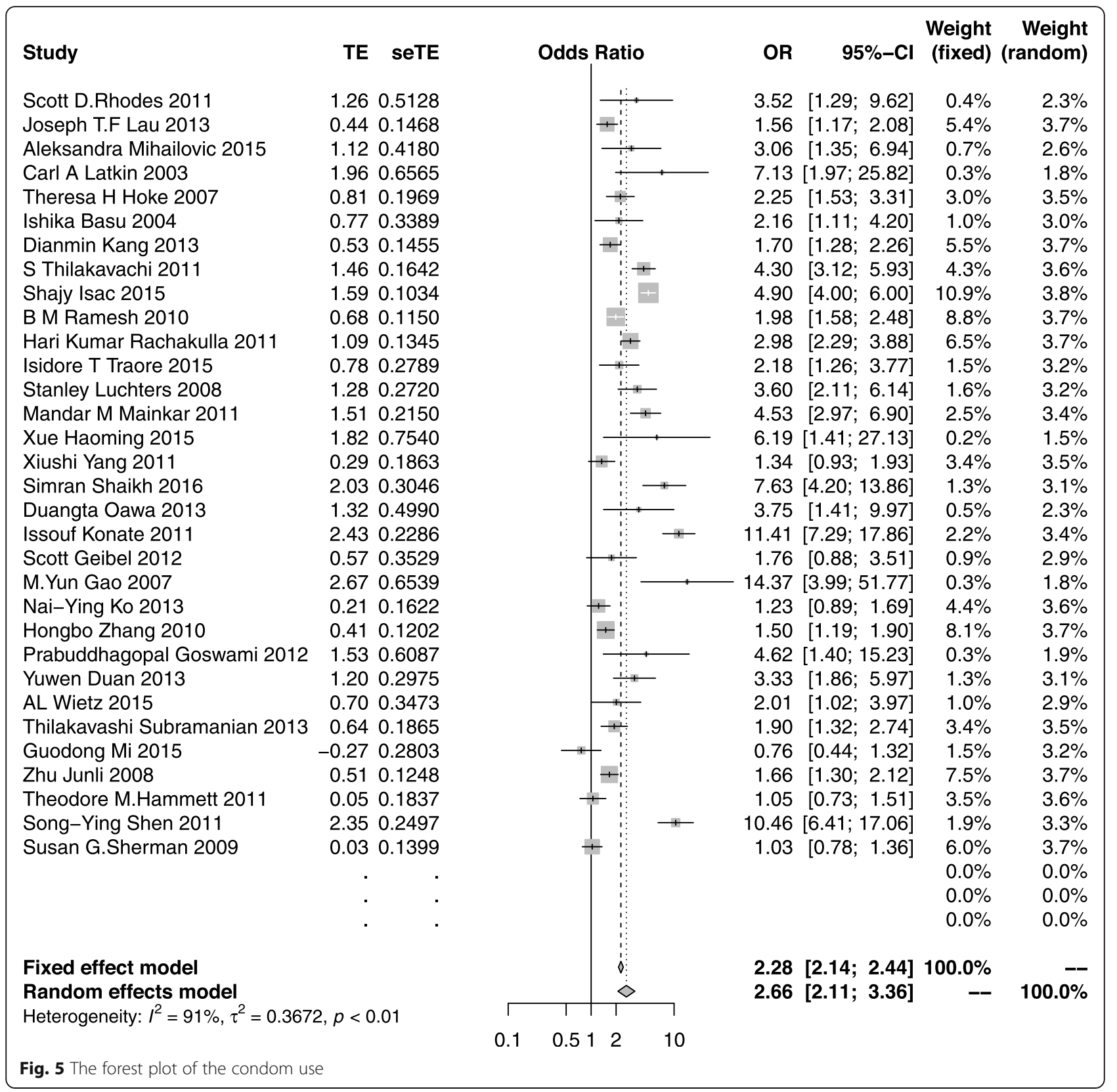

24 months of intervention, the combined effect was 0.32 (95\%CI: 0.16-0.63), suggesting that peer education was still valid in reducing equipment sharing over a long period.

\section{HIV testing}

The persistent effect of peer education on HIV testing was significant with an overall OR of 6.85 after 24 months of intervention, higher than the effects after 3,6, 12 months of 2.54 (95\%CI: 1.35-4.78), 2.36 (95\%CI: 1.21-4.60), 1.78 (95\%CI: 1.26-2.52) collectively. The general increasing trend indicated that peer education had a persistent positive impact on encouraging high risk groups to get an HIV test.

\section{Condom use}

The overall time effect of condom use was positive but variable. During the first year after the intervention, the significant impact decreased with a pooled OR of 1.98 (95\%CI:1.25-3.13), 1.81 (95\%CI:1.25-2.63), 1.54 (95\%CI: 1.35-1.76) after 3, 6,12 months respectively. However after 12 months, the effect began to increase from 1.81 (95\%CI:1.22-2.69) in 24 months to 2.65 (95\%CI:1.624.35 ) in 36 months, and finally reaching 2.86 (95\%CI: 


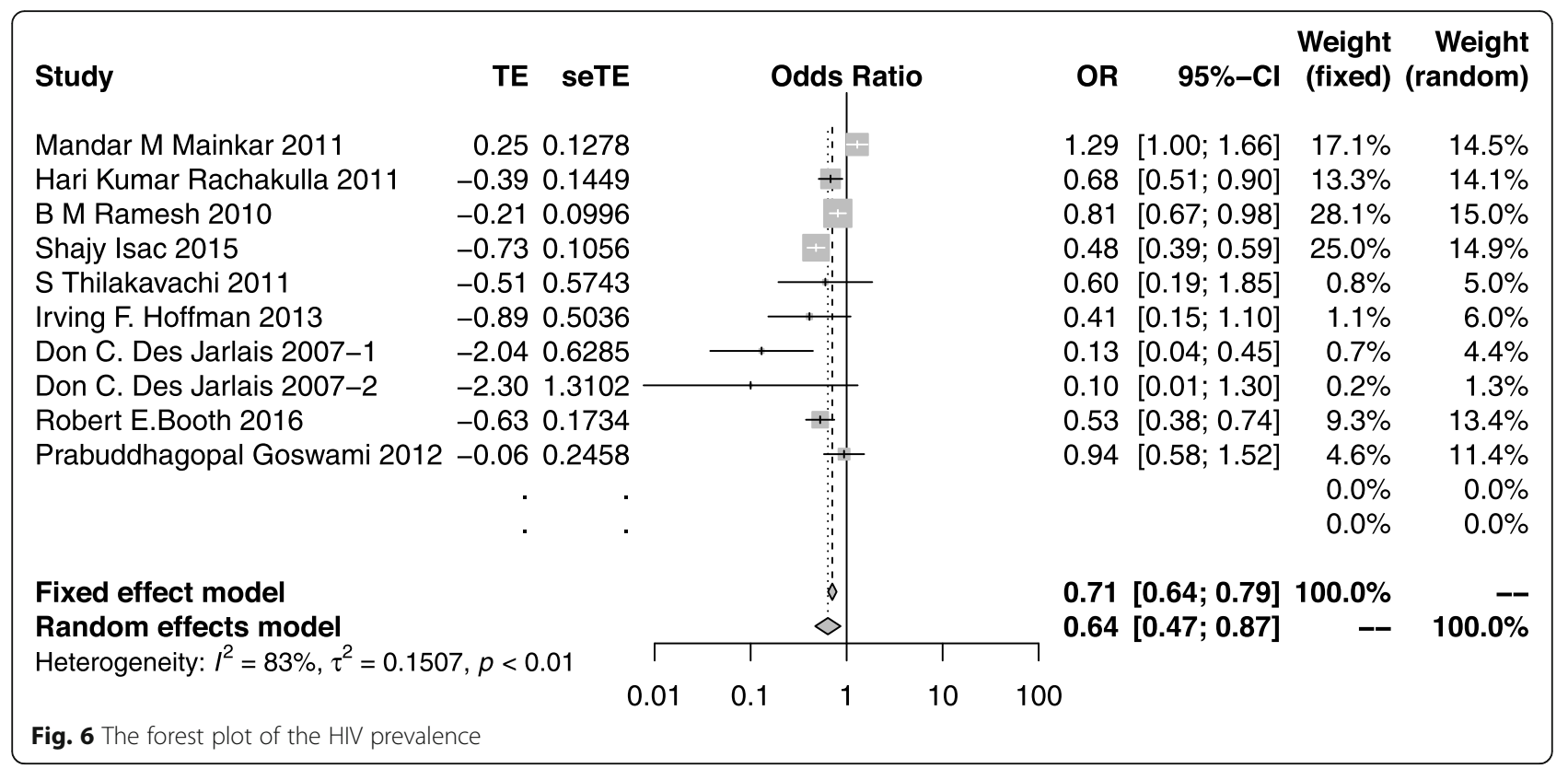

2.2-3.71) in 48 months, suggesting a general persistent effect of peer education on condom use.

\section{E. HIV measure}

The follow-up time of the HIV measure in the studies focused mainly on 1 to 3 years, thus so we conducted the time analysis in 12, 24, 36 months. Results indicated that after 12 months and 24 months intervention, HIV measure significantly declined with a pooled effect of 0.56 (95\%CI:0.43-0.73) and 0.33 (95\%CI:0.20-0.55) respectively. Although it still reduced the HIV measure after 36 months, the intervention effect was not statistically significant (OR:0.77; 95\%CI:0.55-1.09), implying that the preventive effect of HIV measure may have a slight decline over time.

\section{Meta-regression}

For the HIV test, equipment sharing and condom use meta analyses whose heterogeneity were over $90 \%$, a multivariate meta regression was conducted. The meta regression model quantified the impact of the follow-up time, study sites and high risk groups. Supplemental Table 3 highlights that the follow-up time was the source of heterogeneity for both the meta analyses of HIV testing and equipment sharing, while the study sites and high risk groups did not show significant heterogeneity among these three meta analyses. Although the heterogeneity in the meta-analysis of condom use was relatively high, we had not found the source of heterogeneity. After adjusting for the impact of follow-up time, the pooled effect of the meta-analysis was still significant, which was shown in the results of the effect of duration.

\section{Discussion}

We conducted a systematic review and meta-analysis by combining 59 studies to examine the effectiveness of peer education and analyzed its long-term effects among high risk HIV groups in both developed and developing countries.

Our findings revealed that peer education can effectively promote HIV testing, condom use and reduce unprotected sex and HIV measure among MSM, IDUs and FSWs. The time trend analysis has indicated that this intervention can transform the behaviors consistently with significant results for over maximum 24 months. Moreover, peer education had a more significant effect in developing countries than developed countries, indicating that peer education may be particularly suitable in low and middle-income countries.

Our review is consistent with prior meta analyses showing the positive impacts of peer-based intervention for HIV prevention. In line with our results, a meta-analysis conducted in developing countries demonstrated that peer-led interventions could improve condom use with a combined OR of 1.92 among the general population [8]. However, our study indicated a stronger effect with a combined OR of 2.66, mainly because our target was high risk HIV groups who may involve in more sexual activities. Another metaanalysis showed that the odds of undergoing tests for HIV among MSM who were engaged in peer-led intervention were twice as high as counterparts who were not: the authors' results were thus almost the same as our analysis with a combined OR of 2.75 on HIV testing behavior [23]. A previous systematic review found a $32 \%$ reduction in unprotected sex for 


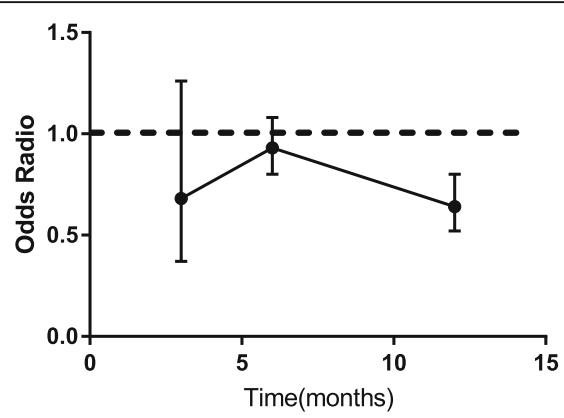

a. unprotected sex

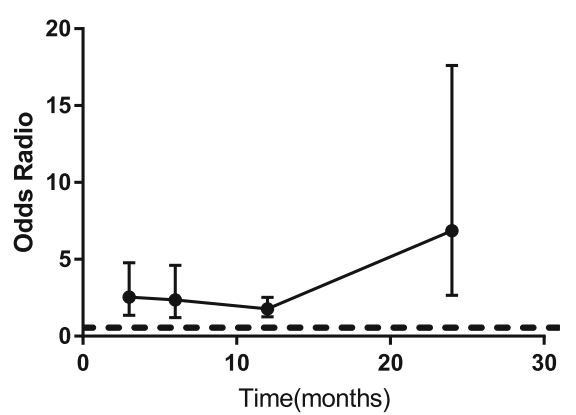

c.HIV testing

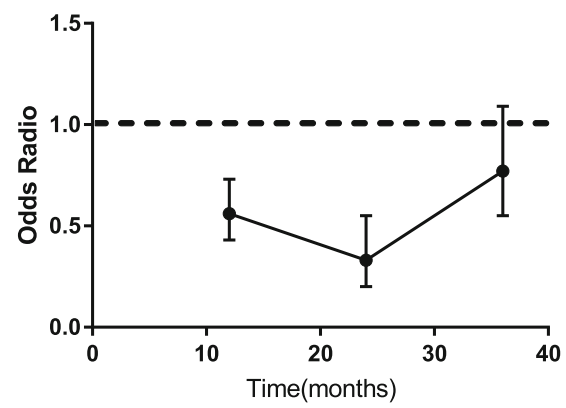

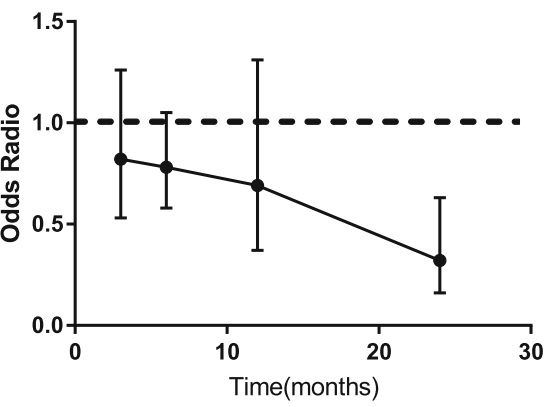

b. equipment sharing

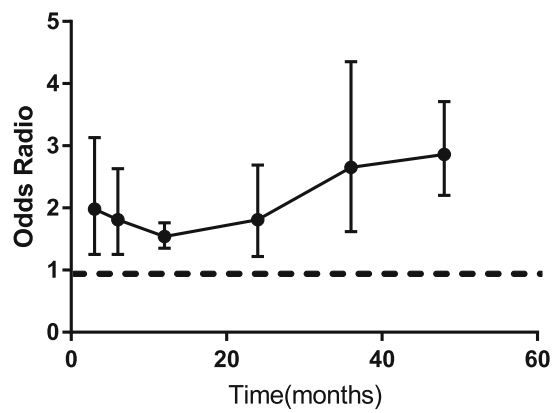

d. general condom use

e. HIV infection

Fig. 7 Time trend of peer education effectiveness among HIV high risk groups

group-based interventions among MSM [27], slightly higher than our study (24\%), which indicated a greater effect among MSM on unprotected sex behavior. We thus believe that our systematic review and meta-analysis contributes to the growing body of work on the utility of peer-led intervention by adding evidence for the critical outcome among high risk HIV groups worldwide.

Our subgroup analyses revealed that peer education has a significant effect on increasing condom use both with casual partners $(\mathrm{OR}=2.79)$ and regular partners $(\mathrm{OR}=2.45)$ as well as on consistent condom use $(\mathrm{OR}=$ 1.80). Condom use has been proven to effectively prevent transmission among high risk HIV groups [66], especially among FSWs. Their regular partners and clients include different types of men, from "boyfriends" and sex work venue managers to "protectors" who prevent the women from being assaulted at night [81]. The HIV risk is probably high among these men who have many sex worker girlfriends [65]. From our findings, we strongly believe that the continuum of peer education was crucial in obtaining a high adherence level of FSWs to use condom with diverse partners. Nevertheless, a recent study by Karnataka suggested that if an FSW started sex work and subsequently acquires a regular sex partner, condoms were more likely to be used, compared with situations where marriage occurs first and sex work begins later on [82]. Thus more work is required to 
understand and mitigate sexual risk and to increase condom use among high risk HIV groups.

We believe that the greatest strength of this study is that we analyzed the time trend of peer education effectiveness among high risk HIV groups. Time analysis verified that peer education has a consistent effect on changing behaviors and reducing HIV incidence over 24 months, although with some fluctuations. The results of HIV testing and condom use were significant overall with a gradual increasing trend, indicating a persistent and positive effect on changing these two behaviors. As regards equipment sharing and unprotected sex, peer education might be able to reduce the occurrence rate significantly after 12 months. The effect became gradually robust which was in accordance with the HIV testing and condom use results. Stages of change (SOCs) revealed that people move through a series of stages when modifying behaviors [83, 84]. The transtheoretical model (TTM) posits that people move through five specific SOCs when changing health behaviors: precontemplation, contemplation, preparation, action, and maintenance [85]. It is therefore normal that the outcomes were not completely clearly or even reversed during the behavior change process.

In terms of HIV infection, which included the time periods of 12, 24, 36 months, the significant results maintained, however the effects weakened at 36 months. There are other factors that may lead to HIV infection, such as economic pressures driving [66], the risk social environment [85], severe stigmatization and discrimination. Other factors, such as the increasing registration for anti-retroviral treatment (ART) among adults and women, and the misconception that people on ART do not transmit HIV, could have contributed to newlyinfected HIV cases [70]. Additional research is needed to identify the structural characteristics of the social networks of high-risk groups that may facilitate more successful peer education intervention.

Our review also has several limitations. First, we found evidence of publication bias in the meta-analysis of HIV testing and unprotected sex. Disproportionate reporting of significant associations in published work can result in an overestimate of the impact of peer education [86]. Therefore, we conducted sensitivity analyses and subgroup analyses in an attempt to reduce biases. Second, when analyzing the time trend of peer education effectiveness, biases might exist in studies which were conducted over a period of 12 months since they were mostly serial cross sectional studies. However, the sample size of those studies was sufficiently large to minimize biases as much as possible. Finally, the heterogeneity across studies was significant, which may overstate the pooled estimates. Considering that subgroup analyses and meta-regression were conducted, we believe that our results are still reliable.

\section{Conclusion}

In conclusion, peer education can effectively change behaviors and reduce HIV measure among high risk HIV groups. More importantly, it can maintain its effects consistently with significant results over 24 months period. Nevertheless, further RCT studies with longer follow-up period are still needed to precisely validate the effect of duration.] In order to significantly reduce the prevalence of HIV, peer education characterized by its low-costing features tend to particularly beneficial for low- and middle-income countries and should be promoted widely in resource-limited regions.

\section{Supplementary information}

Supplementary information accompanies this paper at https://doi.org/10. 1186/s12879-020-05003-9.

\section{Additional file 1. The information of the selected studies. \\ Additional file 2: Table S1. Study quality assessment. Table S2.} The results of egger test.

Additional file 3: Figure S1. The sensitivity analysis of the unprotected sex. Figure S2. The sensitivity analysis of the HIV testing. Figure S3. The sensitivity analysis of the equipment use. Figure $\mathbf{S}$ The sensitivity analysis of the HIV prevalence. Figure S5. The sensitivity analysis of the general condom use. Figure S6. The sensitivity analysis of the consistent condom use. Figure $\mathbf{S 7}$. The sensitivity analysis of the condom use with casual partners. Figure S8. The sensitivity analysis of the condom use with regular partners.

Additional file 4: Figure S9. The forest plot of the condom use among FSWs. Figure S10. The forest plot of the condom use among IDUs. Figure S11. The forest plot of the condom use among MSM. Figure S12. The forest plot of condom use with casual partners. Figure S13. The forest plot of condom use with regular partners. Figure S14. The forest plot of consistent condom use.

\section{Acknowledgements}

The authors wish to thank all study participants for taking part in the study.

\section{Declarations}

Data were collected from researches and literature so there was no ethics issue on this paper.

\section{Authors' contributions}

He JY and Hao YT conceived and designed the study. He JY conducted the research and collected the data. He JY analyzed the data and wrote the fir draft of manuscript. Wang Y, Liao J and Du ZC guided the research and revised the manuscript. He $\mathrm{N}$ gave advice on the manuscript. All authors contributed to data interpretation and writing of the manuscript. All authors have read and approved the final manuscript.

\section{Funding}

This work was supported by grants from the Mega Projects of National Science Research for the 13th Five-Year Plan (2018ZX10715004-001-010). The funder had no role in the study design, data collection and analysis, interpretation of data, and writing the manuscript.

\section{Availability of data and materials}

All data generated or analyzed during this study are included in this published article and its supplementary information files.

Ethics approval and consent to participate

Not applicable.

Consent for publication

Not applicable. 


\section{Competing interests}

The authors declare that they have no competing interests.

\section{Author details}

'Department of Medical Statistics and Epidemiology, School of Public Health, Sun Yat-sen University, Guangzhou 510080, Guangdong Province, China. ${ }^{2}$ Department of Epidemiology, School of Public Health, Fudan University, Shanghai 200032, China. ${ }^{3}$ The Key Laboratory of Public Health Safety of Ministry of Education, Fudan University, Shanghai 200032, China.

Received: 18 August 2019 Accepted: 30 March 2020 Published online: 12 May 2020

\section{References}

1. Solomon SS, Solomon S, McFall AM, Srikrishnan AK, Anand S, Verma V, Vasudevan CK, Balakrishnan P, Ogburn EL, Moulton LH, et al. Integrated HIV testing, prevention, and treatment intervention for key populations in India: a cluster-randomised trial. Lancet Hiv. 2019:6(5):e283-96.

2. Global HIV \& AIDS statistics-2019 fact sheet. https://www.unaids.org/en/ resources/fact-sheet. Accessed 15 Feb 2020.

3. Holtz TH, Pattanasin S, Chonwattana W, Tongtoyai J, Chaikummao S Varangrat A, Mock PA. Longitudinal analysis of key HIV-risk behavior patterns and predictors in men who have sex with men, Bangkok, Thailand. Arch Sex Behav. 2015;44(2):341-8.

4. Kurth AE, Cleland CM, Des Jarlais DC, Musyoki H, Lizcano JA, Chhun N, Cherutich P. HIV prevalence, estimated incidence, and risk behaviors among people who inject drugs in Kenya. J Acquir Immune Defic Syndr. 2015;70(4): 420-7.

5. Burt RD, Tinsley J, Glick SN. A decline in HIV testing among persons who inject drugs in the Seattle area, 2004-2015. J Acquir Immune Defic Syndr. 2017;75(Suppl 3):S346-51.

6. Johnson WD, Diaz RM, Flanders WD, Goodman M, Hill AN, Holtgrave D, Malow R, McClellan WM. Behavioral interventions to reduce risk for sexual transmission of HIV among men who have sex with men. Cochrane Database Syst Rev. 2008;3:D1230.

7. Herbst JH, Beeker C, Mathew A, McNally T, Passin WF, Kay LS, Crepaz N, Lyles CM, Briss P, Chattopadhyay S, et al. The effectiveness of individualgroup-, and community-level HIV behavioral risk-reduction interventions for adult men who have sex with men: a systematic review. Am J Prev Med. 2007;32(4 Suppl):S38-67.

8. Medley A, Kennedy C, O'Reilly K, Sweat M. Effectiveness of peer education interventions for HIV prevention in developing countries: a systematic review and meta-analysis. AIDS Educ Prev. 2009;21(3):181-206.

9. Webel AR. Testing a peer-based symptom management intervention for women living with HIV/AIDS. AIDS Care. 2010;22(9):1029-40.

10. Simoni JM, Nelson KM, Franks JC, Yard SS, Lehavot K. Are peer interventions for HIV efficacious? A systematic review. AIDS Behav. 2011;15(8):1589-95.

11. Campbell C, Mzaidume Z. Grassroots participation, peer education, and HIV prevention by sex workers in South Africa. Am J Public Health. 2001;91(12): 1978-86.

12. Yan H, Zhang R, Wei C, Li J, Xu J, Yang H, McFarland W. A peer-led, community-based rapid HIV testing intervention among untested men who have sex with men in China: an operational model for expansion of HIV testing and linkage to care. Sex Transm Infect. 2014;90(5):388-93.

13. Bagnall AM, South J, Hulme C, Woodall J, Vinall-Collier K, Raine G, Kinsella K, Dixey R, Harris L, Wright NM. A systematic review of the effectiveness and cost-effectiveness of peer education and peer support in prisons. BMC Public Health. 2015;15:290

14. Chola L, Fadnes LT, Engebretsen IM, Nkonki L, Nankabirwa V, Sommerfelt $H$, Tumwine JK, Tylleskar T, Robberstad B. Cost-effectiveness of peer Counselling for the promotion of exclusive breastfeeding in Uganda. PLoS One. 2015;10(11):e142718.

15. Panic N, Leoncini E, de Belvis G, Ricciardi W, Boccia S. Evaluation of the endorsement of the preferred reporting items for systematic reviews and meta-analysis (PRISMA) statement on the quality of published systematic review and meta-analyses. PLoS One. 2013;8(12):e83138.

16. Higgins JP, Thompson SG, Deeks JJ, Altman DG. Measuring inconsistency in meta-analyses. BMJ. 2003;327(7414):557-60.

17. Liu Y, Vermund SH, Ruan Y, et al. Peer counselling versus standard-of-care on reducing high-risk behaviours among newly diagnosed HIV-positive men who have sex with men in Beijing, China: a randomized intervention study. J Int AIDS Soc. 2018;21(2):e25079.

18. Adebajo S, Eluwa G, Njab J, Oginni A, Ukwuije F, Ahonsi B, Lorenc T. Evaluating the effect of HIV prevention strategies on uptake of HIV counselling and testing among male most-at-risk-populations in Nigeria; a cross-sectional analysis. Sex Transm Infect. 2015:91(8):555-60.

19. Mi G, Wu Z, Wang X, Shi CX, Yu F, Li T, Zhang L, McGoogan JM, Pang L, Xu $J$, et al. Effects of a quasi-randomized web-based intervention on risk behaviors and treatment seeking among HIV-positive men who have sex with men in Chengdu, China. Curr Hiv Res. 2015;13(6):490-6.

20. Hidalgo MA, Kuhns LM, Hotton AL, Johnson AK, Mustanski B, Garofalo R. The MyPEEPS randomized controlled trial: a pilot of preliminary efficacy, feasibility, and acceptability of a group-level, HIV risk reduction intervention for young men who have sex with men. Arch Sex Behav. 2015;44(2):475-85.

21. Young SD, Cumberland WG, Nianogo R, Menacho LA, Galea JT, Coates T. The HOPE social media intervention for global HIV prevention in Peru: a cluster randomised controlled trial. Lancet HIV. 2015;2(1):e27-32.

22. Mihailovic A, Tobin K, Latkin C. The influence of a peer-based HIV prevention intervention on conversation about HIV prevention among people who inject drugs in Baltimore, Maryland. Aids Behav. 2015;19(10): 1792-800.

23. Shangani S, Escudero D, Kirwa K, Harrison A, Marshall B, Operario D. Effectiveness of peer-led interventions to increase HIV testing among men who have sex with men: a systematic review and meta-analysis. AIDS Care. 2017;29(8):1003-13.

24. Wong T, Pharr JR, Bungum T, Coughenour C, Lough NL. Effects of peer sexual health education on college campuses: a systematic review. Health Promot Pract. 2019;20(5):652-66.

25. Hu J, Wang X, Guo S, Chen F, Wu YY, Ji FJ, Fang X. Peer support interventions for breast cancer patients: a systematic review. Breast Cancer Res Treat. 2019;174(2):325-41.

26. Rose-Clarke K, Bentley A, Marston C, Prost A. Peer-facilitated communitybased interventions for adolescent health in low- and middle-income countries: a systematic review. PLoS One. 2019;14(1):e210468.

27. Ye S, Yin L, Amico R, Simoni J, Vermund S, Ruan Y, Shao Y, Qian HZ. Efficacy of peer-led interventions to reduce unprotected anal intercourse among men who have sex with men: a meta-analysis. PLoS One. 2014;9(3):e90788.

28. Egger M, Davey SG, Schneider M, Minder C. Bias in meta-analysis detected by a simple, graphical test. BMJ. 1997;315(7109):629-34.

29. Davey-Rothwell MA, Tobin K, Yang C, Sun CJ, Latkin CA. Results of a randomized controlled trial of a peer Mentor HIV/STI prevention intervention for women over an 18 month follow-up. AIDS Behav. 2011; 15(8):1654-63.

30. Surratt HL, O Grady C, Kurtz SP, Levi-Minzi MA, Chen M. Outcomes of a behavioral intervention to reduce HIV risk among drug-involved female sex workers. AIDS Behav. 2014;18(4):726-39.

31. Rhodes SD, McCoy TP, Vissman AT, DiClemente RJ, Duck S, Hergenrather KC, Foley $\mathrm{KL}$, Alonzo J, Bloom FR, Eng E. A randomized controlled trial of a culturally congruent intervention to increase condom use and HV testing among heterosexually active immigrant Latino men. AIDS Behav. 2011;15(8):1764-75.

32. Lau JT, Tsui HY, Lau MM. A pilot clustered randomized control trial evaluating the efficacy of a network-based HIV peer-education intervention targeting men who have sex with men in Hong Kong, China. Aids Care. 2013;25(7):812-9.

33. Wirtz AL, Trapence G, Jumbe V, Umar E, Ketende S, Kamba D, Berry M, Strömdahl S, Beyrer C, Muula AS, et al. Feasibility of a combination HIV prevention program for men who have sex with men in Blantyre, Malawi. JAIDS. 2015;70(2):155-62.

34. Ko NY, Hsieh CH, Wang MC, Lee C, Chen CL, Chung AC, Hsu ST. Effects of internet popular opinion leaders (iPOL) among internet-using men who have sex with men. J Med Internet Res. 2013;15(2):e40.

35. Young SD, Cumberland WG, Lee S, Jaganath D, Szekeres G, Coates T. Social networking technologies as an emerging tool for HIV prevention. Ann Intern Med. 2013;159(5):318.

36. Yuwen Duan HZJW. Community-based peer intervention to reduce HIV risk among men who have sex with men in Sichuan province, China. Aids Educ Prev. 2013;1(25):38-48.

37. Goswami P, Rachakulla HK, Ramakrishnan L, Mathew S, Ramanathan S, George B, Adhikary R, Kodavalla V, Rajkumar H, Paranjape RS, et al. An assessment of a large-scale HIV prevention programme for high-risk men who have sex with men and transgenders in Andhra Pradesh, India: using 
data from routine programme monitoring and repeated cross-sectional surveys. BMJ Open. 2013;3(4):e2183.

38. Subramanian T, Ramakrishnan L, Aridoss S, Goswami P, Kanguswami B, Shajan M, Adhikary R, Purushothaman GKC, Ramamoorthy SK, Chinnaswamy E, et al. Increasing condom use and declining STI prevalence in high-risk MSM and TGs: evaluation of a large-scale prevention program in Tamil Nadu, India. Bmc Public Health. 2013;13(1):857.

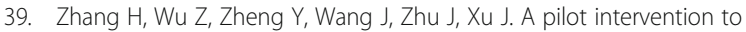
increase condom use and HIV testing and counseling among men who have sex with men in Anhui, China. J Acquir Immune Defic Syndr. 2010; 53(Suppl 1):S88-92.

40. Jun-li Z, Hong-bo Z, Zun-you WU, Ying-jun Z, Juan XU, Jun W, Hong-hua WU, Lin C, Der GJ. HIV risk behavior based on intervention among men who have sex with men peer groups in Anhui province. Chin J Prev Med. 2008;42(12):895-900.

41. Yun Gao M, Wang S. Participatory communication and HIV/AIDS prevention in a Chinese marginalized (MSM) population. AIDS Care. 2007;19(6):799-810.

42. Amirkhanian YA, Kelly JA, Kabakchieva E, Kirsanova AV, Vassileva S, Takacs J, DiFranceisco WJ, McAuliffe TL, Khoursine RA, Mocsonaki L. A randomized social network HIV prevention trial with young men who have sex with men in Russia and Bulgaria. AIDS (London, England). 2005;19(16):1897-905.

43. Williamson LM, Hart GJ, Flowers P, Frankis JS, Der GJ. The gay Men's task force: the impact of peer education on the sexual health behaviour of homosexual men in Glasgow. Sex Transm Infect. 2001;77(6):427-32.

44. Theall KP, Fleckman J, Jacobs M. Impact of a community popular opinion leader intervention among African American adults in a southeastern United States community. AIDS Educ Prev. 2015;27(3):275-87.

45. Jain B, Krishnan S, Ramesh S, Sabarwal S, Garg V, Dhingra N. Effect of peerled outreach activities on injecting risk behavior among male drug users in Haryana, India. Harm Reduct J. 2014;11:3.

46. Go VF, Frangakis C, Le Minh N, Latkin CA, Ha TV, Mo TT, Sripaipan T, Davis W, Zelaya C, Vu PT, et al. Effects of an HIV peer prevention intervention on sexual and injecting risk behaviors among injecting drug users and their risk partners in Thai Nguyen, Vietnam: a randomized controlled trial. Soc Sci Med. 2013;96:154-64.

47. Latkin C, Donnell D, Liu T, Davey-Rothwell M, Celentano D, Metzger D. The dynamic relationship between social norms and behaviors: the results of an HIV prevention network intervention for injection drug users. Addiction. 2013;108(5):934-43.

48. Hoffman IF, Latkin CA, Kukhareva PV, Malov SV, Batluk JV, Shaboltas AV, Skochilov RV, Sokolov NV, Verevochkin SV, Hudgens MG, et al. A peereducator network HIV prevention intervention among injection drug users: results of a randomized controlled trial in St. Petersburg, Russia. AIDS Behav. 2013;17(7):2510-20.

49. Mackesy-Amiti ME, Finnegan L, Ouellet L, Golub ET, Hagan H, Hudson SM, Latka MH, Garfein RS. Peer-education intervention to reduce injection risk behaviors benefits high-risk Young injection drug users: a latent transition analysis of the CIDUS 3/DUIT study. AIDS Behav. 2013;17(6):2075-83.

50. Hammett TM, Des Jarlais DC, Kling R, Kieu BT, McNicholl JM, Wasinrapee P, McDougal JS, Liu W, Chen Y, Meng D, et al. Controlling HIV epidemics among injection drug users: eight years of cross-border HIV prevention interventions in Vietnam and China. PLoS One. 2012;7(8):e43141.

51. Hammett TM, Kling R, Van NTH, Son DH, Binh KT, Oanh KTH. HIV prevention interventions for female sexual Partners of Injection Drug Users in Hanoi, Vietnam: 24-month evaluation results. AIDS Behav. 2012;16(5):1164-72.

52. Tobin KE, Kuramoto SJ, Davey-Rothwell MA, Latkin CA. The STEP into action study: a peer-based, personal risk network-focused HIV prevention intervention with injection drug users in Baltimore, Maryland. Addiction. 2011;106(2):366-75.

53. Shen S, Zhang Z, Tucker JD, Chang H, Zhang G, Lin A. Peer-based behavioral health program for drug users in China: a pilot study. BMC Public Health. 2011;11(1):693.

54. Booth RE, Lehman WE, Latkin CA, Dvoryak S, Brewster JT, Royer MS, Sinitsyna L. Individual and network interventions with injection drug users in 5 Ukraine cities. Am J Public Health. 2011;101(2):336-43.

55. Latkin CA, Donnell D, Metzger D, Sherman S, Aramrattna A, Davis-Vogel A, Quan VM, Gandham S, Vongchak T, Perdue T, et al. The efficacy of a network intervention to reduce HIV risk behaviors among drug users and risk partners in Chiang Mai, Thailand and Philadelphia, USA. Soc Sci Med. 2009;68(4):740-8.

56. Purcell DW, Latka MH, Metsch LR, et al. Results from a randomized controlled trial of a peer-mentoring intervention to reduce HIV transmission and increase access to care and adherence to HIV medications among HIVseropositive injection drug users. J Acquir Immune Defic Syndr. 2007;46 Suppl 2:S35-47.

57. Weeks MR, Li J, Dickson-Gomez J, Convey M, Martinez M, Radda K, Clair S. Outcomes of a peer HIV prevention program with injection drug and crack users: the risk avoidance partnership. Subst Use Misuse. 2009;44(2):253-81.

58. Purcell DW, Latka MH, Metsch LR, Latkin CA, Gómez CA, Mizuno Y, Arnsten $J H$, Wilkinson JD, Knight KR, Knowlton AR et al: Results From a Randomized Controlled Trial of a Peer-Mentoring Intervention to Reduce HIV Transmission and Increase Access to Care and Adherence to HIV Medications Among HIV-Seropositive Injection Drug Users. JAIDS 2007, 46 Suppl 2, HIV prevention and clinical care for HIV-positive injection drug users: lessons from the INSPIRE study (supplement 2):S35-S47.

59. Garfein RS, Golub ET, Greenberg AE, Hagan H, Hanson DL, Hudson SM, Kapadia F, Latka MH, Ouellet LJ, Purcell DW, et al. A peer-education intervention to reduce injection risk behaviors for HIV and hepatitis C virus infection in young injection drug users. AIDS (London, England). 2007. 21(14):1923-32.

60. Des Jarlais DC, Kling R, Hammett TM, Ngu D, Liu W, Chen Y, Binh KT, Friedmann P. Reducing HIV infection among new injecting drug users in the China-Vietnam cross border project. AIDS. 2007;21(Suppl 8):S109-14.

61. Broadhead RS, Volkanevsky VL, Rydanova T, Ryabkova M, Borch C, van Hulst Y, Fullerton A, Sergeyev B, Heckathorn DD. Peer-driven HIV interventions for drug injectors in Russia: first year impact results of a field experiment. INT J DRUG POLICY. 2006;17(5):379-92.

62. Hammett TM. Community Attitudes Toward HIV Prevention for Injection Drug Users: Findings from a Cross-Border Project in Southern China and Northern Vietnam. J Urban Health. 2005;82(3_suppl_4):v34-42.

63. Latkin CA, Sherman S, Knowlton A. HIV prevention among drug users: outcome of a network-oriented peer outreach intervention. Health Psychol. 2003;22(4):332-9.

64. Booth RE, Davis JM, Dvoryak S, Brewster JT, Lisovska O, Strathdee SA, Latkin CA. HIV incidence among people who inject drugs (PWIDs) in Ukraine: results from a clustered randomised trial. The Lancet HIV. 2016;3(10):e482-9.

65. Traore IT, Meda N, Hema NM, Ouedraogo D, Some F, Some R, Niessougou J, Sanon A, Konate I, Van De Perre P, et al. HIV prevention and care services for female sex workers: efficacy of a targeted community-based intervention in Burkina Faso. J Int AIDS Soc. 2015;18(1):20088.

66. Kang D, Tao X, Liao M, Li J, Zhang N, Zhu X, Sun X, Lin B, Su S, Hao L, et al. An integrated individual, community, and structural intervention to reduce HIV/STI risks among female sex workers in China. BMC Public Health. 2013; 13(1):717.

67. Ang A, Morisky DE. A multilevel analysis of the impact of socio-structural and environmental influences on condom use among female sex workers. AIDS Behav. 2012;16(4):934-42.

68. Xiushi Yang GXXL. The efficacy of a peer-assisted multi-component behavioral intervention among female entertainment workers in China: an initial assessment. AIDS Care. 2011;11(23):1509-18.

69. Thilakavathi S, Boopathi K, Girish Kumar CP, Santhakumar A, Senthilkumar R, Eswaramurthy C, llaya Bharathy V, Ramakrishnan L, Thongamba G, Adhikary $\mathrm{R}$, et al. Assessment of the scale, coverage and outcomes of the Avahan HIV prevention program for female sex workers in Tamil Nadu, India: is there evidence of an effect? Bmc Public Health. 2011;11 Suppl 6(Suppl 6):S3.

70. Rachakulla HK, Kodavalla V, Rajkumar H, Prasad SPV, Kallam S, Goswami P, Dale J, Adhikary R, Paranjape R, Brahmam GNV. Condom use and prevalence of syphilis and HIV among female sex workers in Andhra Pradesh, India - following a large-scale HIV prevention intervention. Bmc Public Health. 2011;11 Suppl 6(Suppl 6):S1.

71. Konate I, Traore L, Ouedraogo A, Sanon A, Diallo R, Ouedraogo JL, Huet C, Millogo I, Andonaba JB, Mayaud P, et al. Linking HIV prevention and care for community interventions among high-risk women in Burkina Faso--the ARNS 1222 "Yerelon" cohort. J Acquir Immune Defic Syndr. 2011;57(Suppl 1):S50-4.

72. Mainkar MM, Pardeshi DB, Dale J, Deshpande S, Khazi S, Gautam A, Goswami P, Adhikary R, Ramanathan S, George B, et al. Targeted interventions of the Avahan program and their association with intermediate outcomes among female sex workers in Maharashtra, India. Bmc Public Health. 2011;11 Suppl 6:S2.

73. Ramesh BM, Beattie TSH, Shajy I, Washington R, Jagannathan L, Reza-Paul S, Blanchard JF, Moses S. Changes in risk behaviours and prevalence of sexually transmitted infections following HIV preventive interventions 
among female sex workers in five districts in Karnataka state, South India. Sex Transm Infect. 2010;86(Suppl 1):i17-24.

74. Luchters S, Chersich MF, Rinyiru A, Barasa MS, King'Ola N, Mandaliya K, Bosire W, Wambugu S, Mwarogo P, Temmerman M. Impact of five years of peer-mediated interventions on sexual behavior and sexually transmitted infections among female sex workers in Mombasa, Kenya. Bmc Public Health. 2008;8:143

75. Xue H, Luo Z, Zhu Z, Yang X, Yang L, Yang J, Duo L, Liu W. Intervention caused changes in high risk sex behaviors among female sex workers from Vietnam in Yunnan, 2009-2013. Zhonghua Liu Xing Bing Xue Za Zhi. 2015; 36(9):941-4.

76. Geibel S, King'Ola N, Temmerman M, Luchters S. The impact of peer outreach on HIV knowledge and prevention behaviours of male sex workers in Mombasa, Kenya. Sex Transm Infect. 2012;88(5):357-62.

77. Hoke TH, Feldblum PJ, Damme KV, Nasution MD, Grey TW, Wong EL, Ralimamonjy L, Raharimalala L, Rasamindrakotroka A. Randomised controlled trial of alternative male and female condom promotion strategies targeting sex workers in Madagascar. Sex Transm Infect. 2007; 83(6):448-53.

78. Ishika Basu SJMJ. HIV prevention among sex Workers in India. J Acquir Immune Defic Syndr. 2004;3(36):845-52.

79. Shaikh S, Mburu G, Arumugam V, Mattipalli N, Aher A, Mehta S, Robertson J. Empowering communities and strengthening systems to improve transgender health: outcomes from the Pehchan programme in India. J Int Aids Soc. 2016;19(3 Suppl 2):20809.

80. Pawa D, Firestone R, Ratchasi S, Dowling O, Jittakoat $Y$, Duke A, Mundy G. Reducing HIV risk among transgender women in Thailand: a quasiexperimental evaluation of the sisters program. PLoS One. 2013;8(10): e77113.

81. Wang C, Hawes SE, Gaye A, Sow PS, Ndoye I, Manhart LE, Wald A, Critchlow CW, Kiviat NB. HIV prevalence, previous HIV testing, and condom use with clients and regular partners among Senegalese commercial sex workers. Sex Transm Infect. 2007;83(7):534-40.

82. Isac S, Prakash R, Ramesh BM, et al. Challenges in increasing condom use among female sex workers with their regular sex partners in Karnataka state, South India. Washington DC: International AIDS Conference; 2012.

83. Helitzer DL, Peterson AB, Sanders M, Thompson J. Relationship of stages of change to attendance in a diabetes prevention program. Am J Health Promot. 2007;21(6):517-20.

84. Prochaska JO, DiClemente CC. Stages and processes of self-change of smoking: toward an integrative model of change. J Consult Clin Psychol. 1983;51(3):390-5.

85. Tseng HM, Liao SF, Wen YP, Chuang YJ. Stages of change concept of the transtheoretical model for healthy eating links health literacy and diabetes knowledge to glycemic control in people with type 2 diabetes. Prim Care Diabetes. 2017;11(1):29-36.

86. Yuan T, Fitzpatrick T, Ko NY, Cai Y, Chen Y, Zhao J, Li L, Xu J, Gu J, Li J, et al. Circumcision to prevent HIV and other sexually transmitted infections in men who have sex with men: a systematic review and meta-analysis of global data. Lancet Glob Health. 2019;7(4):e436-47.

\section{Publisher's Note}

Springer Nature remains neutral with regard to jurisdictional claims in published maps and institutional affiliations.

Ready to submit your research? Choose BMC and benefit from:
- fast, convenient online submission
- thorough peer review by experienced researchers in your field
- rapid publication on acceptance
- support for research data, including large and complex data types
- gold Open Access which fosters wider collaboration and increased citations
- maximum visibility for your research: over 100M website views per year
At BMC, research is always in progress.
Learn more biomedcentral.com/submissions

